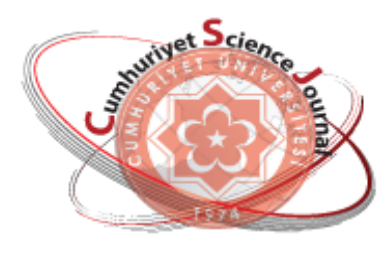

e-ISSN: 2587-246X

ISSN: $2587-2680$

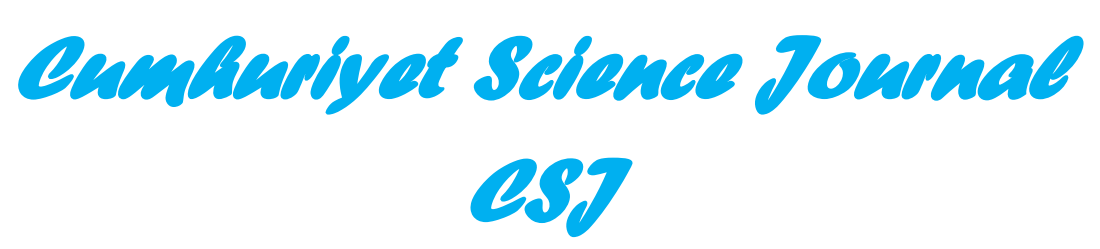

Cumhuriyet Sci. J., Vol.39-3(2018) 714-719

\title{
Optical Properties of Tuned Double Quantum Well Under the Electric Field
}

\author{
Esin KASAPOĞLU
}

Cumhuriyet University, Faculty of Science, Department of Physics, Sivas TURKEY

Received: 27.07.2018; Accepted: 13.08.2018

http://dx.doi.org/10.17776/csj.448572

\begin{abstract}
In this study, the effects of the electric field and structure-tune parameter on the linear, third order nonlinear and total absorption coefficients for transitions between the first three bound states of an electron confined within the tuned GaAs/ GaAlAs double quantum well are investigated. The obtained results show that the absorption spectra is susceptible to the structure parameter and the electric field. By changing the structure parameter and intensity of the electric field, it can be adjusted a blue or red shift in the absorption spectra according to purpose and these results can be used to tune and control the optical properties of tuned double quantum well.
\end{abstract}

Keywords: Double quantum well, Absorption coefficient, Electric field.

\section{Ayarlanmış Çift Kuantum kuyusunun Elektrik Alan Altındaki Optik Özellikleri}

Özet. Bu çalışmada, ayarlanmış GaAs / GaAlAs çift kuantum kuyusunda kuşatılan bir elektronun ilk üç bağlı düzeyi arasındaki geçişler için doğrusal, 3. mertebeden doğrusal olmayan ve toplam soğurma katsayıları üzerinde elektrik alan ve yapı-ayar parametresinin etkileri incelendi. Elde edilen sonuçlar, soğurma spektrumunun yapı -ayar parametresine ve elektrik alan şiddetine duyarlı olduğunu göstermektedir. Elektrik alan şiddeti ve yapı parametresi değiştirilerek, soğurma spektrumunun amaca göre, maviye veya kırmızıya kayması ayarlanabilir ve bu sonuçlar ayarlanmış çift kuantum kuyusunun optik özelliklerini ayarlamak ve kontrol etmek için kullanılabilir.

Anahtar Kelimeler: Çift kuantum kuyusu; Soğurma katsayısı; Elektrik alan

\section{INTRODUCTION}

The effects of the applied external perturbations such as the pressure, temperature, electric, magnetic and intense laser field on the electronic and optical properties of the single, double or multiple quantum wells which have various confinement potential types are important topics of condensed matter physics and these effects have been extensively studied in different situations [112]. Intersubband transitions within the conduction band of quantum wells have unique properties which are including a large dipole moment or oscillator strengths [13], an ultrafast relaxation times [14] and a large tunability of transition wavelength. So, there is extraordinary interest in optical phenomena based on intersubband transitions in low-dimensional semiconductor systems [15-19]. Studies continue intensely to development optoelectronic devices such as infrared detectors, quantum cascade lasers and photodetectors [20-23].

Double, triple or multiple quantum wells provide optical features required for devices design and Stark effect, which can be used to control and 
modulate the output intensity of the devices. The double quantum wells (DQW) are the characteristic examples of the bilayer systems and the electric field strongly modify the quantum states of bilayer systems and also their electronic and optical properties more than that of single quantum well: (i) The electron energy levels shift due to the Stark effect. (ii) Electric field causes a new charge distribution in the coupled wells and shift of electron energy levels due to modification of confinement potential. (iii) The electric field enhances tunneling effect due to the well width and barrier height. Furthermore, if coupling between wells is weak, energy levels have twofold degeneracy. The electric field destroys this degeneracy. In the asymmetric DQW, Stark effect is enhanced quite dramatically since energy levels are not degenerate.

In this paper, we have studied the effects of the electric field and structure parameter on the total absorption coefficient including linear and third order nonlinear absorption coefficients for transitions between the first three energy levels of an electron that confined within the tuned $\mathrm{GaAs} / \mathrm{GaAlAs} \mathrm{DQW}$. This potential profile used in this study is entirely new and has not been studied in the literature so far, is extremely useful for simulating the molecular states of the lowdimensional systems, especially quantum wells.

\section{THEORY}

Time independent Schrödinger equation for the electron in the tuned-DQW under the electric field is given by

$-\frac{\hbar^{2}}{2 m^{*}} \frac{d^{2} \psi(z)}{d z^{2}}+V(z) \psi(z)+e F z \psi(\mathrm{z})=\mathrm{E}_{\mathrm{z}} \psi(\mathrm{z})$

where $\mathrm{m}^{*}$, e and $\mathrm{F}$ denote the electron effective mass, the elementary charge and the electric field that is applied parallel to the growth direction (zdirection), $V(z)$ is the confinement potential and it is defined by

$V(z)=4 V_{0}\left(\left(\frac{z}{\sigma}\right)^{12}-\left(\frac{z}{\sigma}\right)^{6}\right)$

where, $V_{0}$ and $\sigma$ define the well depth and width, respectively. After the subband energies and their corresponding wave functions were obtained, we also calculated the linear, third-order nonlinear and total absorption coefficient for the transitions between any two electronic states by employing the density matrix formalism and the perturbation expansion method. In the two-level system approach, linear, third-order nonlinear and total absorption coefficients (AC) related to the intersubband transitions $i \rightarrow j$ are given as follows [24-26]

$$
\begin{gathered}
\beta^{(1)}(\omega)=\omega \sqrt{\frac{\mu_{o}}{\varepsilon_{r}}} \frac{\left|M_{i j}\right|^{2} \sigma_{v} \hbar \Gamma_{i j}}{\left(E_{i j}-\hbar \omega\right)^{2}+\left(\hbar \Gamma_{i j}\right)^{2}}, \\
\beta^{(3)}(\omega)=-2 \omega \sqrt{\frac{\mu_{o}}{\varepsilon_{r}}}\left(\frac{I}{\varepsilon_{o} n_{r} c}\right) \frac{\left|M_{i j}\right|^{4} \sigma_{v} \hbar \Gamma_{i j}}{\left[\left(E_{i j}-\hbar \omega\right)^{2}+\left(\hbar \Gamma_{i j}\right)^{2}\right]^{2}} \\
\left(1-\frac{\left|M_{j j}-M_{i i}\right|^{2}}{\left|2 M_{i j}\right|^{2}} \frac{\left(E_{i j}-\hbar \omega\right)^{2}-\left(\hbar \Gamma_{i j}\right)^{2}+2 E_{i j}\left(E_{i j}-\hbar \omega\right)}{E_{i j}^{2}+\left(\hbar \Gamma_{i j}\right)^{2}}\right), \\
\beta(\omega)=\beta^{(1)}(\omega)+\beta^{(3)}(\omega),
\end{gathered}
$$


where, $\varepsilon_{r}=n_{r}^{2} \varepsilon_{0}$ is the real part of the permittivity $n_{r}$ is the refractive index of the system, $\varepsilon_{0}$ is the vacuum permittivity, $\sigma_{V}$ is the carrier density in the system, $\mu_{o}$ is the vacuum permeability, $\Delta E=$ $E_{i j}=E_{j}-E_{i}$ is the energy difference between any two electronic states, $M_{i j}=\left|\left\langle\psi_{i}|e z| \psi_{j}\right\rangle\right|,(i, j=1,2,3) \quad$ is $\quad$ the transition element between the eigenstates $\psi_{i}$ and $\psi_{j}$ for z polarization of the incident radiation, $\Gamma_{\mathrm{ij}}$ -the relaxation rate which is equals to the inverse relaxation time $\mathrm{T}_{\mathrm{ij}}, c$ is the light speed in free space, and $I$ is the optical intensity of incident photon with the $\omega$-angular frequency that leads to the intersubband optical transitions.

\section{RESULTS AND DISCUSIONS}

The parameters used in numerical calculations are $\varepsilon_{\mathrm{O}}=12.58, \mathrm{~m}^{*}=0.0665 m_{\mathrm{o}}$ (where $\mathrm{m}_{\mathrm{O}}$ is the free electron mass), $V_{o}=228 \mathrm{meV}, \mathrm{n}_{\mathrm{r}}=3.2$, $\mathrm{T}_{12}=0.2 \mathrm{ps}\left(\Gamma_{12}=1 / T_{12}\right)$,

$\mu_{\mathrm{o}}=4 \pi \times 10^{-7} \mathrm{Hm}^{-1}, \quad \sigma_{\mathrm{v}}=3.0 \times 10^{22} \mathrm{~m}^{-3}$ and $I=5.0 \times 10^{8} \mathrm{~W} / \mathrm{m}^{2}$. In the figures, blue (red) lines are for $\sigma=100 \AA$ ( $\sigma=75 \AA)$.

In Fig.1, the changes of the confinement potential profile and the squared wave functions corresponding to ground, first and second excited state energy level of the electron confined in the tuned DQW as a function of the position are plotted for two different $\sigma$ values (where, $\sigma$ is the well width and it will be called as a structure or tune parameter): (a) $\mathrm{F}=0$, (b) $\mathrm{F}=50 \mathrm{kV} / \mathrm{cm}$. Blue (red) line is for $\sigma=100 \AA(\sigma=75 \AA)$. As seen in these figures: (i) As the $\sigma$ increases, the electronic localization in the well increases while the coupling between the wells decreases. (ii) Electric field effect is more pronounced in the large $\sigma-$ value. (iii) Tuned DQW tilts towards the opposite direction of the electric field with the electric field effect, electron in the ground (first excited) state localized in the left (right) well and the second excited state is almost unaffected since the electron in this level are located in the quantum well with $2 \sigma$ width and has more energy than that of the electrons in other states.
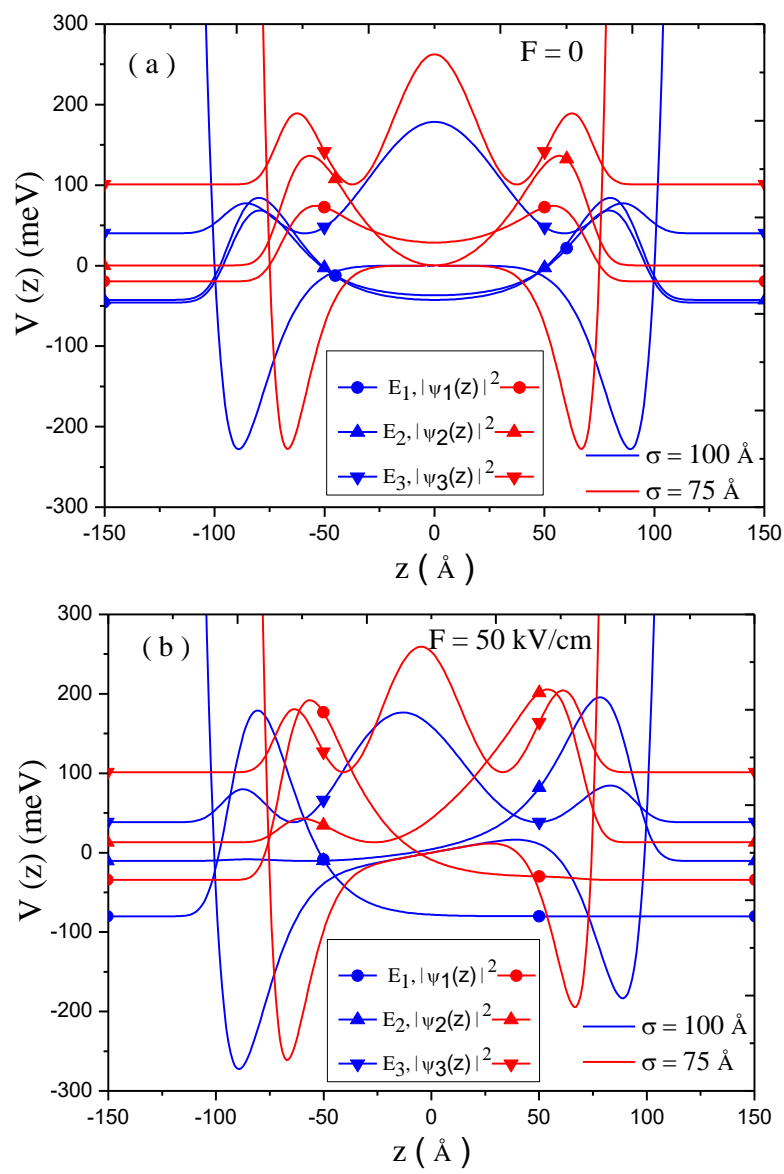

Figure 1. The changes of the confinement potential profile and the squared wave functions corresponding to ground, first and second excited state energy levels of the electron confined in the tuned DQW as a function of the position for two different $\sigma$ values: (a) $\mathrm{F}=0$, (b) $\mathrm{F}=50 \mathrm{kV} / \mathrm{cm}$. Blue (red) line is for $\sigma$ $=100 \AA(\sigma=75 \AA)$.

In the Figs. 2 (a) and 2 (b), we present the changes of linear, nonlinear and total $\mathrm{AC}$ for the transitions between the first three electronic states in tuned DQW for $\sigma=100 \AA$ versus the incident photon energy for $F=0$ and $F=50 \mathrm{kV} / \mathrm{cm}$, respectively. As seen in Fig. 2(a), the transition of (1-3) is forbidden due to the symmetry of the structure, the absorption peak position for the (2-3) transition is located at high photon energies than that of the (12) transition, due to the energy difference between the related energy levels $\left(\Delta E_{23}>\Delta E_{12}\right)$, the peak 
magnitude of total AC corresponding to the (1-2) transition becomes negative due to the tremendous contribution of the third-order nonlinear AC, and the resonant peak of total AC for the (2-3) transition is divided into peaks which is attributed to bleaching effect. When the electric field is applied, the (1-3) transition becomes allowed since the symmetry of the structure lifts, absorption peak corresponding to the (1-2) transition shifts to the blue while it shifts to the red for the (2-3) transition. It should be noted that, if the energy difference between any two electronic states increases with the effect of electric field, the peak absorption energy also increases and this case can be explained by the quantum confined Stark effects (QCSE). Results with and without electric field for the changes of ACs versus the photon energies are given in Figs. 3 (a) and 3 (b), for $\sigma=75 \AA$. if compared to the previous figures, a blue shift is observed in the ACs corresponding to both of the transitions while there is no electric field and $\mathrm{AC}$ corresponding to the (1-2) transition shifts to the lower photon energies. When the electric field is applied and the $\sigma$-parameter decreases, only a significant change in the amplitude of the absorption peak of the (1-2) transition is observed. As is known, the changes observed in peak amplitudes are related to the transition matrix element.

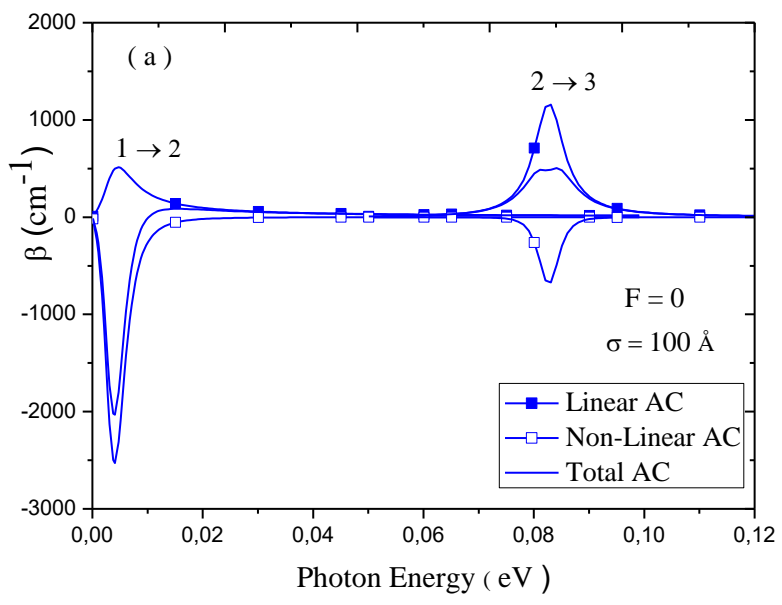

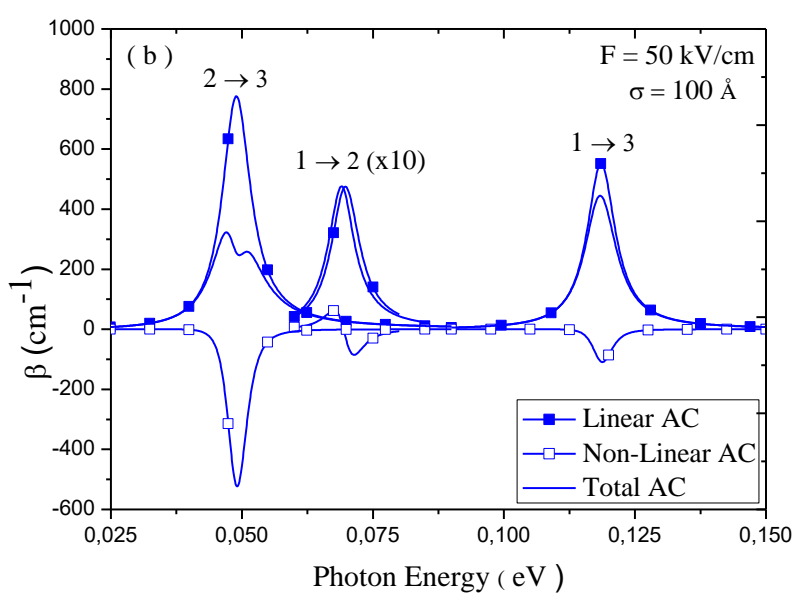

Figure 2. The changes of linear, nonlinear and total $\mathrm{AC}$ for the transitions between the first three electronic states in tuned DQW versus the incident photon energy for $\sigma=100 \AA$ : (a) $\mathrm{F}=$ 0 , (b) $\mathrm{F}=50 \mathrm{kV} / \mathrm{cm}$.

As seen in the Eqs. (3) and (4), the linear and nonlinear terms of AC are proportional to $\left|M_{i j}\right|^{2}$ and $\left|M_{i j}\right|^{4}$, respectively. If $M_{i j}$ decreases (increases) due to external parameters, the contribution of the nonlinear term decreases (increases) since the nonlinear term of AC is more dominant than that of the linear term and so the magnitude of total AC increases (decreases).

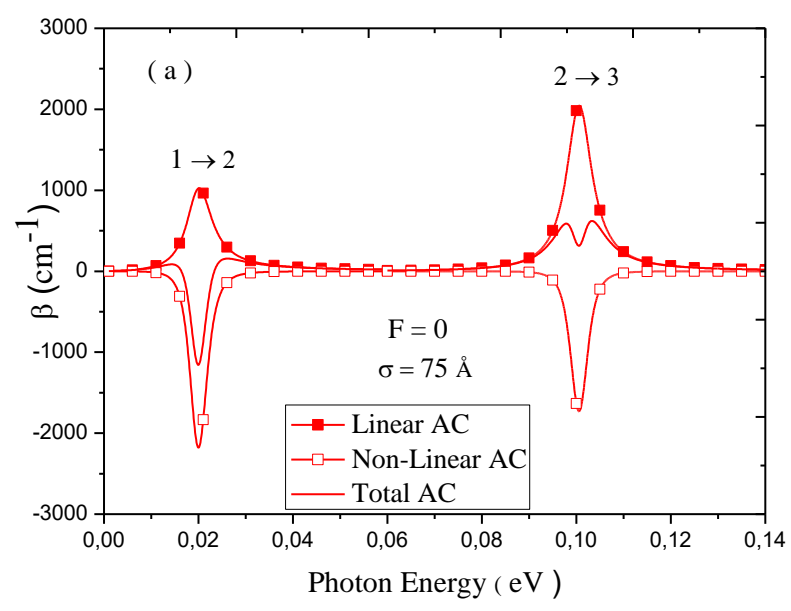




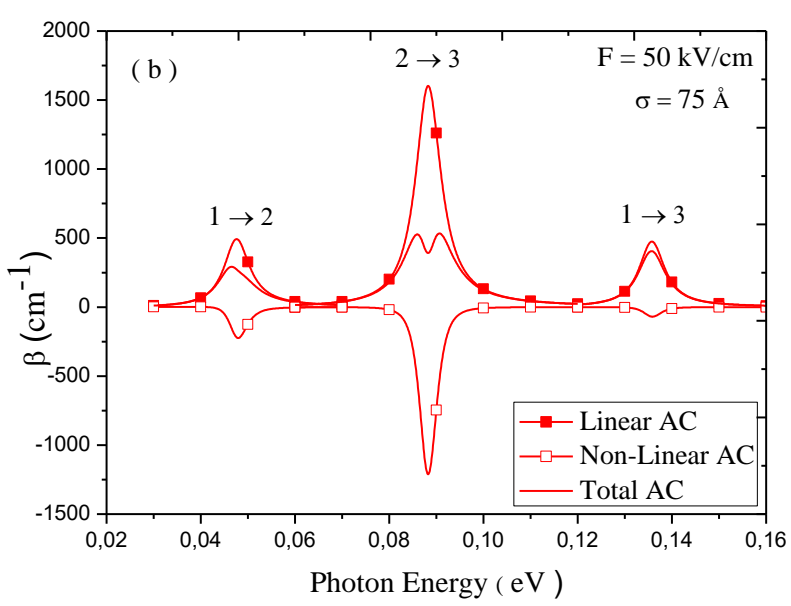

Figure 3. The changes of linear, nonlinear and total AC for the transitions between the first three electronic states in tuned DQW versus the incident photon energy for $\sigma=75 \AA$ : (a) $F=$ 0 , (b) $\mathrm{F}=50 \mathrm{kV} / \mathrm{cm}$.

\section{CONCLUSIONS}

In this study, the effects of the electric field and structure-tune parameter on the linear and third order nonlinear and total absorption coefficients for intersubband transitions between the first three energy levels of an electron that confined in the tuned GaAs/GaAlAs double quantum well are investigated. By changing these parameters, the peak amplitudes and the location of the peak positions can be changed accordingly. These results show that both electric and optical properties of the structure can be changed according to goal.

\section{Acknowledgments}

The authors are grateful to The Scientific Research Project Fund of Cumhuriyet University (CUBAP) under the project number F-557.

\section{REFERENCES}

[1]. Woldemariam M. M., Nonlinear Intersubband Optical Absorption Coefficient and Refractive Index Changes in Asymmetric Parabolic Double Quantum Wells, Journal of Advanced Physics 1 ( 2017) 121-125.

[2]. Karimi M. J., Keshavarz A., Second harmonic generation in asymmetric double semiparabolic quantum wells: Effects of electric and magnetic fields, hydrostatic pressure and temperature, Physica E 44 (2012)1900-1904.

[3]. Hakimyfard A., Barseghyan M. G., Kirakosyan A. A., Simultaneous effects of pressure and magnetic field on intersubband optical transitions in Pöshl-Teller quantum well, Physica E 41 (2009) 1596-1599.

[4]. Eseanu N., Simultaneous effects of laser field and hydrostatic pressure on the intersubband transitions in square and parabolic quantum wells, Physics Letters A 374 (2010) 12781285.

[5]. Wong K. M., Allsopp D. W. E., Intersubband absorption modulation in coupled double quantum wells by external bias, Semicond. Sci. Technol. 24 (2009) 045018 -045025.

[6]. Mora-Ramos M. E., Morales A. L., Duque C. A., Optical Responses in Asymmetric Inverse Parabolic Quantum Wells: Effects of Laser Fields and Hydrostatic Pressure, Acta Physica Polonica A 125-2 (2014) 202-204.

[7]. Niculescu E., Iorga, A., Radu A., Optical Stark Effect in Semiconductor Quantum Wells: A Comparatıve Study, U.P.B. Sci. Bull., Series A 70-3 (2008) 51-58.

[8]. Lima F. M. S., Amato M. A., Nunes O. A. C., Fonseca A. L. A., Enders B. G., E. F. da Silva, Jr., Unexpected transition from single to double quantum well potential induced by intense laser fields in a semiconductor quantum well, J. Appl. Phys. 105 (2009) 123111-123117.

[9]. Gudwani M., Prasad V., Jha P. K., Mohan M., Intersubband Transitions in Coupled Quantum wells under an intense Laser Field, International Journal of Nanoscience 7 (2008) 215-221.

[10].Filikhin I., Karoui A., Vlahovic B., Single electron tunneling in double and triple quantum wells, International Journal of Modern Physics B 30 (2016) 16420111642019 .

[11].Martinz S.D.G., Ramos R.V., Double quantum well triple barrier structures: analytical and numerical results, Can. J. Phys. 94 (2016) 1180-1188.

[12].Silotia P., Giri R., Prasad V., Engineering optical properties of double quantum well 
systems, Indian Journal of Pure \& Applied Physics 54 (2016) 641-650.

[13].West L.C., Eglash S.J., First observation of an extremely large-dipole infrared transition within the conduction band of a GaAs quantum well, Appl. Phys. Lett., 46 (1985) 1156-1158.

[14].Baier J., Bayanov I.M., Plödereder U., Seilmeier A., Biexponential intersubband relaxation in n-modulation-doped quantumwell structures. Superlattices Microstructures, 19 (1996) 9-16.

[15].Cen L. B., Shena B., Qin Z. X., Zhang G. Y., Influence of applied electric fields on the absorption coefficient and subband energy distances of intersubband transitions in AlN/GaN coupled double quantum wells, J. Appl. Phys., 104 (2008) 063114-063117.

[16].Sari H., Ungan F., Sakiroglu S., Yesilgul U., Sökmen I., The effects of intense laser field on optical responses of n-type delta doped GaAs quantum well under applied electric and magnetic fields, Optik 162 (2018) 76-80.

[17].Karabulut I., Nonlinear optical response in intersubband transitions of a symmetric quantum well: Role of electron-electron interactions, Superlattices and Microstructures 111 (2017) 181-187.

[18].Rodríguez-Magdaleno K.A., MartínezOrozco J.C., Rodríguez-Vargas I., MoraRamos M.E., Duque C.A., Asymmetric GaAs n-type double $\delta$-doped quantum wells as a source of intersubband-related nonlinear optical response: Effects of an applied electric field, Journal of Luminescence 147 (2014) 77 84.
[19].Kosionis S.G., Terzis A. F., Paspalakis E., Transient four-wave mixing in intersubband transitions of semiconductor quantum wells, Journal of Luminescence 140 (2013) 130-134.

[20].Levine B. F., Gunapala S. D., Kopf R. F., Photovoltaic GaAs quantum well infrared detectors at $4.2 \mu \mathrm{m}$ using indirect $\mathrm{Al}_{x} \mathrm{Ga}_{1-x}$ barriers, Appl. Phys. Lett. 58 (1991) 15511553.

[21].Levine B. F., Quantum-well infrared photodetectors, J. Appl. Phys., 74 (1993) R1R81.

[22].Faist J., Capasso F., Sivco D. L., Sirtori C., Hutchinson A. L., Cho A. Y., Quantum cascade laser, Science 264 (1994) 553-556.

[23].Kumar S., Williams B. S., Kohen S., Hu Q., Reno J. L., Continuous-wave operation of terahertz quantum-cascade lasers above liquid-nitrogen temperature, Appl. Phys. Lett. 84 (2004) 2494-2496.

[24].Vahdani M. R. K., Rezaei G., Intersubband optical absorption coefficients and refractive index changes in a parabolic cylinder quantum dot, Phys. Lett. A 374 (2010) 637-643.

[25].Ozturk E, Nonlinear intersubband transitions in asymmetric double quantum wells as dependent on intense laser field, Opt. Quant. Electron. 48 (2016) 269-282.

[26].Nazari M., Karimi M.J., Keshavarz A., Linear and nonlinear optical absorption coefficients and refractive index changes in modulationdoped quantum wells: Effects of the magnetic field and hydrostatic pressure, Physica B 428 (2013) 30-35. 